\section{Simulating Future Urban Expansion in Monastir, Tunisia, as an Input for the Development of Future Risk Scenarios}

Gl_Forum 2019, Issue 1

Page: 3 - 9

Short Paper

Corresponding Author: harb@ehs.unu.edu

DOI: 10.1553/giscience2019_01_s3

Mostapha Harb', Michael Hagenlocher', Davide Cotti', Elke Kratzschmar'2, Hayet Baccouche $^{2}$, Karem Ben Khaled2', Felicitas Bellert2, Bouraoui Chebili3, Anis Ben Fredj3 3 , Sonia Ayed ${ }^{3}$, Matthias Garschagen 1,4

'United Nations University Institute for Environment and Human Security (UNU-EHS), Germany 2Industrieanlagen-Betriebsgesellschaft mbH (IABG mbH), Germany ${ }^{3}$ Municipality of Monastir, Tunisia ${ }^{4}$ Ludwig-Maximilians-Universität München (LMU), Germany

\begin{abstract}
Under scenarios of urbanization coupled with increasing frequency and intensity of natural hazards, urban disaster risk is set to rise. Simulating future urban expansion can provide relevant information for the development of future exposure scenarios and the identification of targeted risk reduction and adaptation strategies. Here, we present an urban growth simulation for the coastal city of Monastir, Tunisia. The approach integrates local knowledge and a data-driven urban growth model to simulate urban sprawl up to 2030. A business-as-usual projection is used to predict the future growth of the city based on the historical trend. Thirteen Landsat images for the period 1975 to 2017 were used to delineate past changes in urban land cover following the European Urban Atlas standard, which served as the main input for the urban growth model. The simulation revealed that the city's residential area is likely to grow by 127 ha to an overall size of 1,690 ha by 2030 , corresponding to an increase of $8.1 \%$ compared to the urban footprint of 2017 . The outcomes of the analysis presented here served as an input for the spatial simulation of future exposure to flash floods in the case study area.
\end{abstract}

\title{
Keywords:
}

urban growth, urbanization, SLEUTH, future projection, exposure

\section{Introduction}

A detailed understanding of whether, where and how cities are growing within or into potential hazard-prone areas (e.g. flood zones) is an urgent prerequisite for assessing future risk trajectories and informing decision making in the context of risk-informed, preventive urban planning (Garschagen \& Romero-Lankao, 2015). However, such analysis has been largely overlooked so far, as most climate change and disaster risk research in urban areas has focused primarily on the development of future hazard scenarios (e.g. Dankers \& Feyen, 
2008) and less on the assessment of how urban growth projections might affect future exposure. Urban growth and expansion modelling provides a powerful tool in this context, given that urban growth is one of the key drivers of future exposure to disaster risk in cities (Cardona et al., 2012; Schumacher \& Strobl, 2011).

Within the broader context of the EU-funded research project 'Urban Disaster Resilience through Risk Assessment and Sustainable Planning' (UD-RASP), the objective of this study is to simulate potential urban growth in the city of Monastir, Tunisia, up to 2030, in order to inform scenarios of future urban exposure to flash flood hazards in the city.

\section{Materials and methods}

\subsection{Study area}

Monastir is a mid-sized coastal city located in Tunisia (Latitude: $35^{\circ} 46^{\prime} 40.76^{\prime \prime} \mathrm{N}$, Longitude: $10^{\circ} 49^{\prime} 34.21^{\prime \prime}$ E) with an area of 5,010 ha and a population of approximately 104,000 according to the 2014 Census (National Institute of Statistics, 2017). The city occupies a peninsula on a semi-flat plain, bordering the Mediterranean to the North and to the East, and is prone to multiple hazards, including flash floods and coastal erosion. Over recent decades, rapid urban growth has led to an increase of impervious surfaces, which, coupled with lacking or poorly maintained infrastructure (e.g. drainage systems), has resulted in an increase in flash floods in Monastir.

\subsection{Methodology}

Drawing on a transdisciplinary project design, the methodology presented here integrates a data-driven approach based on historical time-series remote sensing data with local expert knowledge on urbanization drivers and expected future development pathways derived from two scenario workshops. Combining the two sets of information, a projection of future urban growth up to 2030 was developed.

\section{Participatory scenario workshops}

A first scenario workshop was held in October 2017 in Monastir, with the aims of identifying relevant drivers of urban growth in the study area, and of delineating areas that are unlikely to be affected by future urban expansion (e.g. industrial zones and wetlands). Thirty stakeholders participated in the workshop, including representatives from local and regional government as well as civil society. A series of participatory exercises was conducted during the scenario workshop to identify which land use/land cover (LULC) classes are most likely to attract future urban growth. A second scenario workshop was held in May 2018 to present and cross-validate the findings of the initial simulation.

\section{SLEUTH urban growth model}

SLEUTH, a cellular automata (CA) model developed by USGS in 1996, has been used to simulate future urban growth and has been applied in more than 50 cities globally (NCGIA, 2018). The model simulates urban growth by establishing the probability of land-use 
conversion to urban classes, based on a set of growth rules (Oguz, 2005; KantaKumar et al., 2011; Chaudhuri \& Clarke, 2013). The model is based on extracting the urban growth patterns of an area from historical data (e.g. derived from multi-temporal remote sensing data), and then using these patterns to simulate various potential future growth scenarios (Xian et al., 2005; Clarke et al., 1997).

The following datasets were used as an input for the SLEUTH urban growth model (UGM), covering the different criteria indicated in the model's acronym:

1. Slope: Multi-temporal satellite data (World View 3) was used as a baseline for deriving a digital terrain model (DTM) with a spatial resolution of $1 \mathrm{~m}$, which served as an input for the UGM. A slope layer was derived from the $1 \mathrm{~m}$ DTM and resampled to $30 \mathrm{~m}$ to fit the other model inputs. The layer was used to determine the influence of slope on urbanization. A threshold of 15 degrees was adopted following guidelines by NCGIA (2018).

2. Land use: Publicly available remote sensing data from the Landsat programme was used to develop LULC maps for the period 1975 to 2017 following the European Urban Atlas standard, and to evaluate LULC changes. The images were semiautomatically classified based on the LULC classes that best describe the urban setting in Monastir (e.g. residential, industrial, arable, coastal wetland, green urban areas, etc.).

3. Exclusion: This layer defines areas that are not likely to be converted into residential urban areas in the future (e.g. airport, industrial zones, coastal wetlands, etc.), as defined during the scenario workshops.

4. Urban extent: This layer represents the urban extent (urban vs non-urban) according to the historical data derived from the 13 Landsat images.

5. Transportation network: The historical street network was manually extracted from Landsat data for the period 1975-2014 and from historical aerial flights for the years 1984 and 2005.

6. Hillshade: A hillshade layer was created based on the DTM and used as a tool for data visualization.

In order to calibrate the model, SLEUTH was used in 'calibration' mode and trained to derive the growth patterns of Monastir from the historical data. SLEUTH calibration is one of the most critical and intricate phases of the urban growth simulation (Oguz, 2005; Qi, 2012). It uses the spatial information of the past (here: remote sensing data for the period 1975-2017) to forecast the present as a "well-known future". By comparing the model predictions and the actual observations, the calibration process can be adjusted to improve the ability of the model to replicate the reality (KantaKumar et al., 2011). In this application, the common Lee-Sallee metric calibration measure was used as the main quality measure for the model, as it is one of the few metrics that assess the spatial fit (Dietzel \& Clarke, 2007; Qi, 2012; Hui-Hui et al., 2012). The metric is the ratio of the intersection and the union of the simulated and actual urban areas in the control years (Dietzel \& Clarke, 2007; Qi, 2012). It ranges between 0 and 1, with 1 representing the perfect match between the actual and the simulated urban growth in the control years. 


\section{Results and discussion}

\subsection{Urban growth from 1975 to 2017}

The analysis of multi-temporal remote sensing data revealed that the residential areas have grown by $98.9 \%$ since 1975 . The increase of the urban areas was mainly at the expense of agricultural land outside and green spaces within the city. The rapid urbanization process in Monastir is directly linked to the rise of economic activities, notably in the industrial sector, which expanded in the south of the city, and the development of tourist areas along the northern coastal strips. This economic expansion generated significant in-migrations from other areas of the country (Rejeb et al., 2016). The analysis has also shown that residential urban areas in Monastir expanded by 81.07\% between 1975 and 1999. In subsequent years, the city went through a phase of slower expansion or semi-stagnation, mainly due to the limitation of available land for urban development.

\subsection{Calibration}

The model calibration revealed a Lee-Sallee index score of 0.61 (on a scale from 0 to 1 ), which is considered satisfactory according to similar applications in the literature (Dietzel \& Clarke, 2007; Rafiee, et al., 2009). The SLEUTH model output forecasts that expansion due to adjacency to present urban cells (edge growth) will be the principal factor of Monastir's urban growth.

\subsection{Future urban growth up to 2030}

Figure 1 shows the simulated increase in urban areas (in hectares) by 2030 for the businessas-usual $(\mathrm{BaU})$ projection. The results show that the city will probably grow by an additional 127 ha if the historical growth patterns continue. Moreover, the model predicted that $37 \%$ (47 ha) of the estimated growth will happen between 2021 and 2024.

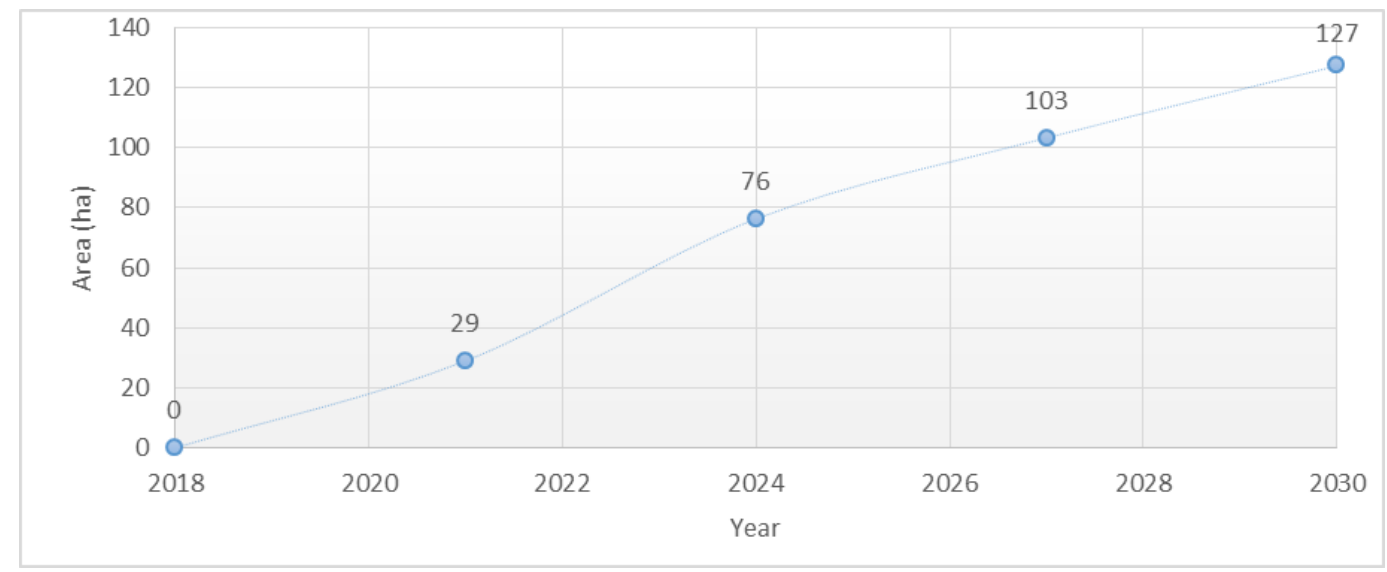

Figure 1: Expected urban growth up to 2030 according to the business-as-usual projection 
Furthermore, as the projection carried out yielded a probabilistic layer, we aggregated the area of the city zones according to their likelihood of being developed by 2030 . Thus, five levels of growth likelihood were considered $(51-60 \%, 61-70 \%, 71-80 \%, 81-90 \%, 91-$ $100 \%$ ). Figure 2 shows the development in hectares for these five ranges.

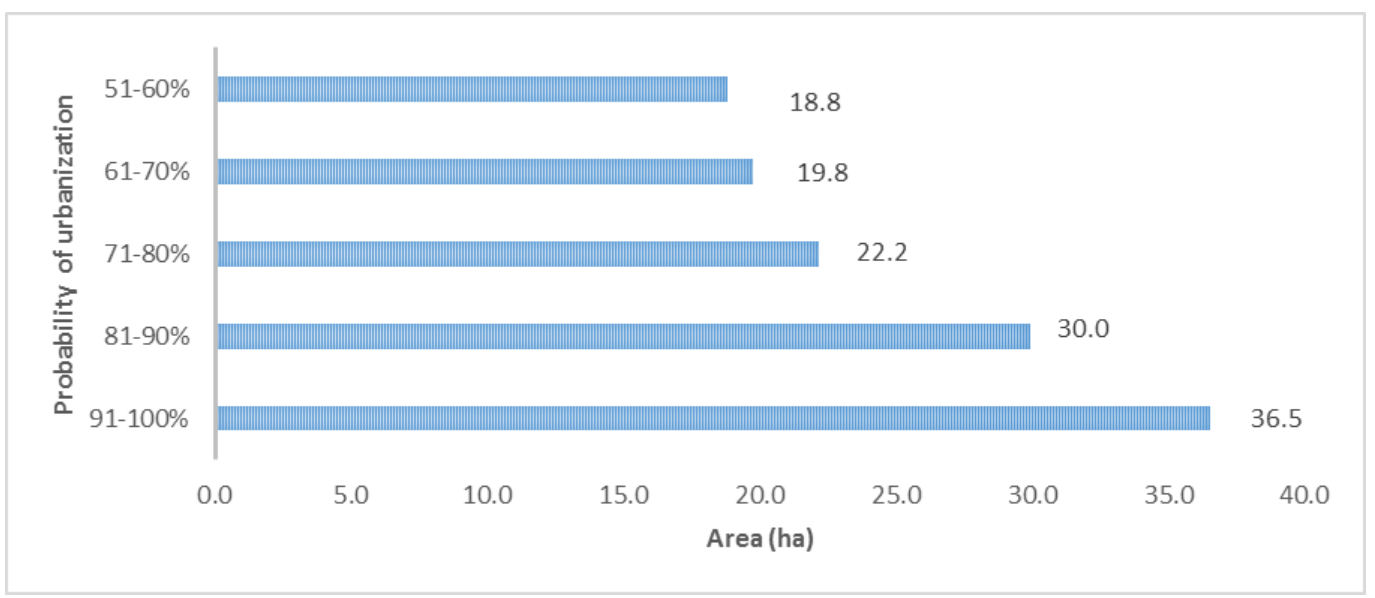

Figure 1: Potential area requirements for urban growth in Monastir by 2030

At the same time, the analysis has revealed that in specific areas of the city, availability and affordability of land will generate a faster urban growth rate. In addition, the proposal for the new city plan 2018 suggested converting several areas of Monastir from non-urban to urban development areas, which is expected to further accelerate the spatial growth of the city (Urban management proposed plan, 2018).

The analysis shows how and where the city will potentially grow over the next 12 years. Based on the $\mathrm{BaU}$ simulation that was conducted, the city is likely to grow by an additional 127 ha to an overall size of 1,690 ha by 2030 , corresponding to growth of $8.1 \%$ compared to 2017. The analysis also reveals that urban growth up until 2030 will be mainly in the form of in-fills and expansion of urban areas along the fringes of the city. Thus, the decline of agricultural land use would be due mainly to the urban expansion in the southern part of the city (Kortine). This is supported by the recently proposed reclassification of the land use in Monastir, which will have a significant role in shaping the city by 2030 .

SLEUTH facilitates the integration of the underlying root causes with the historical growth patterns through a semi-rule-based model. Thus the model implementation represents an opportunity for designing a comprehensive urban growth model that considers local knowledge along with statistical growth patterns, and thus for refining the model's performance accordingly. However, the intrinsic uncertainties of the study must be acknowledged, carefully considered and evaluated, from the preparation of the input (land cover, urban morphology, transportation, slope and exclusion) to the overall performance of the model. Nevertheless, the model outputs potentially allow a "scenario analysis" for urban growth to be carried out that would take into account various development trends. 


\section{Conclusions and outlook}

This study has helped to understand how and where the city of Monastir might grow over the next 12 years, given the current historical trend. The results can serve as a critical input for modelling scenarios of the city's future exposure to flash floods. (These scenarios, together with scenarios of future societal vulnerability, have been developed in a subsequent step (Hagenlocher et al., 2019).) The scenario analysis conducted here presents an opportunity for evaluating and visualizing the potential impacts of the existing city plans and policies on future urban growth. Furthermore, when combined with future scenarios of exposure and vulnerability, such analysis can make a significant contribution to riskinformed, preventive urban planning.

\section{References}

Cardona, O. D., van Aalst, M. K., Birkmann, J., Fordham, M., McGregor, G., \& Mechler, R. (2012). Managing the Risks of Extreme Events and Disasters to Advance Climate Change Adaptation. Cambridge, UK: Cambridge University Press.

Chaudhuri, G., \& Clarke, K. (2013). The SLEUTH land use change model: A review. Environmental Resources Research, 1(1), 88-105.

Clarke, K. C., Hoppen, S., \& Gaydos, L. (1997). A self-modifying cellular automaton model of historical urbanization in the San Francisco bay and Washington bay area. Environment and planning B: Planning and design, 24(2), 247-261.

Dankers, R., \& Feyen, L. (2008). Climate change impact on flood hazard in Europe: An assessment based on high-resolution climate simulations. Journal of Geophysical Research: Atmospheres, 113(D19).

Dietzel, C., \& Clarke, K. C. (2007). Toward optimal calibration of the SLEUTH land use change model. Transactions in GIS, 11(1), 29-45.

Garschagen, M. \& Romero-Lankao, P. (2015). Exploring the relationships between urbanization trends and climate change vulnerability. Climatic Change, 133(1), 37 - 52. doi: 10.1007/s10584013-0812-6

Hagenlocher, M., Harb, M., Cotti, D., Bellert, F., Fila, K., Baccouche, H., Ayed, S., Malmberg, R. \& Garschagen. M. (2019). Assessing current and future urban flash flood risk integrating qualitative and quantitative approaches: lessons from Monastir, Tunisia. Geophysical Research Abstracts Vol. 21, EGU2019-19181.

Hui-Hui, F. E. N. G., Hui-Ping, L. I. U., \& Ying, L. Ü. (2012). Scenario prediction and analysis of urban growth using SLEUTH model. Pedosphere, 22(2), 206-216.

KantaKumar, L. N., Sawant, N. G., \& Kumar, S. (2011). Forecasting urban growth based on GIS, RS and SLEUTH model in Pune metropolitan area. International journal of geomatics and geosciences, 2(2), 568.

National Institute of Statistics. (2017, 8 05). Retrieved from The National Institute of Statistics: http://www.ins.tn

NCGIA. (2018). Project Gigalopolis. Retrieved from Project Gigalopolis:

http://www.ncgia.ucsb.edu/projects/gig/index.html

Oguz, H. (2005). Modeling urban growth and land use/land cover change in the Houston Metropolitan Area from 2002-2030 (Doctoral dissertation, Texas A\&M University).

Qi, L. (2012). Urban land expansion model based on SLEUTH: A case study in Dongguan city, China. Lund, Sweden: Lund University -Department of Physical Geography and Ecosystem Sciences. 
Rafiee, R., Mahiny, A. S., Khorasani, N., Darvishsefat, A. A., \& Danekar, A. (2009). Simulating urban growth in Mashad City, Iran through the SLEUTH model (UGM). Cities, 26(1), 19-26.

Rejeb, A., Claramunt, C., \& Rejeb, H. (2016). New inductive urban and peripheral constructions of diffuse landscapes: about certain observable forms in the region of Monastir. In International Conference Arquitectonics Network: Mind, Land and Society, Barcelona, 1-3 June 2016: Abstracts. GIRAS. Universitat Politècnica de Catalunya.

Schumacher, I., \& Strobl, E. (2011). Economic development and losses due to natural disasters: The role of hazard exposure. Ecological Economics, 72, 97-105.

Urban management proposed plan. (2018). Monastir city proposed plan. Monastir: Municipality of Monastir

Xian, G., Crane, M., \& Steinwand, D. (2005). Dynamic modeling of Tampa Bay urban development using parallel computing. Computers \& Geosciences, 31(7), 920-928. 